\title{
Prediction of gas/particle partitioning of polybrominated diphenyl ethers (PBDEs) in global air: A theoretical study
}

\author{
Y.-F. Li ${ }^{1,2,3}$, W.-L. Ma ${ }^{1}$, and M. Yang ${ }^{2}$ \\ ${ }^{1}$ International Joint Research Center for Persistent Toxic Substances (IJRC-PTS), \\ State Key Laboratory of Urban Water Resource and Environment/School of Municipal \\ and Environmental Engineering, Harbin Institute of Technology, Harbin 150090, China \\ ${ }^{2}$ IJRC-PTS, Dalian Maritime University, Dalian 116026, China \\ ${ }^{3}$ IJRC-PTS-NA, Toronto, Ontario M2N 6X9, Canada \\ Correspondence to: Y.-F. Li (ijrc_pts_paper@yahoo.com)
}

Received: 28 July 2014 - Published in Atmos. Chem. Phys. Discuss.: 10 September 2014 Revised: 22 December 2014 - Accepted: 2 January 2015 - Published: 18 February 2015

\begin{abstract}
Gas/particle (G/P) partitioning of semi-volatile organic compounds (SVOCs) is an important process that primarily governs their atmospheric fate, long-range atmospheric transport, and their routes of entering the human body. All previous studies on this issue are hypothetically based on equilibrium conditions, the results of which do not predict results from monitoring studies well in most cases. In this study, a steady-state model instead of an equilibrium-state model for the investigation of the G/P partitioning behavior of polybrominated diphenyl ethers (PBDEs) was established, and an equation for calculating the partition coefficients under steady state $\left(K_{\mathrm{PS}}\right)$ of PBDEs $\left(\log K_{\mathrm{PS}}=\log K_{\mathrm{PE}}+\log \alpha\right)$ was developed in which an equilibrium term $\left(\log K_{\mathrm{PE}}=\log K_{\mathrm{OA}}+\log f_{\mathrm{OM}}-11.91\right.$ where $f_{\mathrm{OM}}$ is organic matter content of the particles) and a nonequilibrium term ( $\log \alpha$, caused by dry and wet depositions of particles), both being functions of $\log K_{\mathrm{OA}}$ (octanol-air partition coefficient), are included. It was found that the equilibrium is a special case of steady state when the nonequilibrium term equals zero. A criterion to classify the equilibrium and non-equilibrium status of PBDEs was also established using two threshold values of $\log K_{\mathrm{OA}}, \log K_{\mathrm{OA} 1}$, and $\log K_{\mathrm{OA} 2}$, which divide the range of $\log K_{\mathrm{OA}}$ into three domains: equilibrium, non-equilibrium, and maximum partition domain. Accordingly, two threshold values of temperature $t, t_{\mathrm{TH} 1}$ when $\log K_{\mathrm{OA}}=\log K_{\mathrm{OA} 1}$ and $t_{\mathrm{TH} 2}$ when $\log K_{\mathrm{OA}}=\log K_{\mathrm{OA} 2}$, were identified, which divide the range of temperature also into the same three domains for each PBDE congener. We predicted the existence of the maximum
\end{abstract}

partition domain (the values of $\log K_{\mathrm{PS}}$ reach a maximum constant of -1.53 ) that every PBDE congener can reach when $\log K_{\mathrm{OA}} \geq \log K_{\mathrm{OA} 2}$, or $t \leq t_{\mathrm{TH} 2}$. The novel equation developed in this study was applied to predict the G/P partition coefficients of PBDEs for our Chinese persistent organic pollutants (POPs) Soil and Air Monitoring Program, Phase 2 (China-SAMP-II) program and other monitoring programs worldwide, including in Asia, Europe, North America, and the Arctic, and the results matched well with all the monitoring data, except those obtained at e-waste sites due to the unpredictable PBDE emissions at these sites. This study provided evidence that the newly developed steady-state-based equation is superior to the equilibrium-state-based equation that has been used in describing the G/P partitioning behavior over decades. We suggest that the investigation on $\mathrm{G} / \mathrm{P}$ partitioning behavior for PBDEs should be based on steady state, not equilibrium state, and equilibrium is just a special case of steady state when non-equilibrium factors can be ignored. We also believe that our new equation provides a useful tool for environmental scientists in both monitoring and modeling research on G/P partitioning of PBDEs and can be extended to predict $\mathrm{G} / \mathrm{P}$ partitioning behavior for other SVOCs as well.

\section{Introduction}

Atmospheric transport is a major mechanism of moving semi-volatile organic compounds (SVOCs), including persistent organic pollutants (POPs), from source regions to other 
remote places including the Arctic and Antarctic, where these chemicals have never been produced and used (Barrie et al., 1992; Macdonald et al., 2000; Li et al., 1998; Li and Bidleman, 2003; Eckhardt and Manø, 2007). The gas/particle (also called aerosol) (G/P) partitioning of SVOCs is a very important process that primarily governs their atmospheric fate (Lohmann et al., 2000), since wet and dry depositions and other processes act differently on gaseous and particulate SVOCs, thus affecting the efficiency and scope of their long-range atmospheric transport and fate (Bidleman, 1988). In addition, SVOCs are an important class of indoor pollutants that are of great concern to human health (Weschler and Nazaroff, 2008). The gaseous and particulate SVOCs have different routes of entering the human body, and therefore the G/P partitioning of SVOCs has a significant influence on human exposure (Weschler, 2003).

The G/P partitioning behavior of SVOCs, $K_{\mathrm{P}}$, is commonly defined as (Yamasaki et al., 1982, Pankow 1991, Pankow and Bidleman 1991)

$K_{\mathrm{P}}=\left(C_{\mathrm{P}} / \mathrm{TSP}\right) / C_{\mathrm{G}}$,

where $C_{\mathrm{G}}$ and $C_{\mathrm{P}}$ are concentrations of SVOCs in gas and particle phases (both in $\mathrm{pg} \mathrm{m}^{-3}$ of air), respectively, and TSP is the concentration of total suspended particles in air $\left(\mu \mathrm{g} \mathrm{m}^{-3}\right)$. Thus, $K_{\mathrm{P}}$ is measured in units of $\mathrm{m}^{3} \mu \mathrm{g}^{-1}$. In this study, the term of partition quotient instead of partition coefficient is used for $K_{\mathrm{P}}$ because partition coefficient is used for equilibrium conditions only, and Eq. (1) was not defined under equilibrium conditions.

The value of $K_{\mathrm{P}}$, calculated by Eq. (1) using the monitoring data TSP, $C_{\mathrm{P}}$, and $C_{\mathrm{G}}$, is denoted as $K_{\mathrm{PM}}$ (subscript "M" in $K_{\mathrm{PM}}$ means measurement). It has been shown that there is a linear relationship between $\log K_{\mathrm{PM}}$ and $\log K_{\mathrm{OA}}\left(K_{\mathrm{OA}}\right.$ is the octanol-air partition coefficient) (Finizio et al., 1997, Harner and Bidleman, 1998, Pankow, 1998) and between $\log K_{\mathrm{PM}}$ and $\log P_{\mathrm{L}}\left(P_{\mathrm{L}}\right.$ is sub-cooled liquid vapor pressure) (Pankow, 1987; Bidleman and Foreman, 1987; Pankow and Bidleman, 1991, 1992). The $\log K_{\mathrm{OA}}$-based model given by

$\log K_{\mathrm{PR}}=m_{\mathrm{O}} \log K_{\mathrm{OA}}+b_{\mathrm{O}}$

has been widely used in describing the partitioning behavior of SVOCs, where slope $m_{\mathrm{O}}$ and intercept $b_{\mathrm{O}}$ are fitting constants obtained using regression of $\log K_{\mathrm{PM}}$ (from Eq. 1) against $\log K_{\mathrm{OA}}$. The subscript " $\mathrm{R}$ " in $K_{\mathrm{PR}}$ indicates regression.

Unfortunately, Eq. (2) is not very useful to environmental modelers since this equation can only be used when the monitoring data of SVOCs concentrations in both gas and particle phases are known; however, modelers need the equations to predict environmental behavior, including concentrations in air with both gas and particle phases, based on physicochemical properties of SVOCs, their emissions, and climate and meteorological conditions.

Under the conditions of the equilibrium $\left(m_{\mathrm{O}}=1\right)$, the dominant absorption processes between gas and particle phases, and equivalence of octanol to the sorbing organic matter in particle, Harner and Bidleman (1998) derived the following equation:

$\log K_{\mathrm{PE}}=\log K_{\mathrm{OA}}+\log f_{\mathrm{OM}}-11.91$,

where $f_{\mathrm{OM}}$ is organic matter content of the particle. The subscript "E" in $K_{\mathrm{PE}}$ indicates equilibrium. In comparison to Eq. (2), Eq. (3) has the advantage of predicting $K_{\mathrm{PE}}$ from the values of $K_{\mathrm{OA}}$ and $f_{\mathrm{OM}}$ without the need for real monitoring data.

However, as discussed in previous publications (Finizio et al., 1997; Cetin and Odabasi, 2007; Tian et al., 2011; Yang et al., 2013; Li and Jia, 2014), Eq. (3) cannot describe accurately the relationship between gas- and particle-phase polybrominated diphenyl ethers (PBDEs). It is evident that Eq. (3) can be applied only in a few cases, such as for lessbrominated PBDE congeners (such as BDE-17 and -28) or at high temperatures, and becomes inaccurate in most cases, especially for highly brominated PBDE congeners, such as BDE-66, -85, -99, -100, -153, -154, and -183, or at low temperatures (Yang et al., 2013; Li and Jia, 2014). This has been blamed on the artifacts and non-equilibrium factors (Finizio et al., 1997; Cetin and Odabasi, 2007; Tian et al., 2011; Su et al., 2006).

Based on a large data set of more than 700 pairs of air samples in both gas and particle phases with a wide ambient temperature range of $60^{\circ} \mathrm{C}$ from -22 to $+38^{\circ} \mathrm{C}$ obtained from our Chinese POPs Soil and Air Monitoring Program, Phase 2 (China-SAMP-II), we investigated the G/P partitioning behavior of PBDEs in Chinese air (Yang et al., 2013; Li and Jia, 2014). We derived for the first time empirical equations to predict the values of slopes and intercepts for both $K_{\mathrm{OA}^{-}}$ based and $P_{\mathrm{L}}$-based models as functions of temperature, and thus the predicted partition quotient $\left(K_{\mathrm{P}}\right)$, without assuming an equilibrium status and free of artifacts (Li and Jia, 2014). The slope $m_{\mathrm{O}}$ and the intercept $b_{\mathrm{O}}$ were given as functions of temperature (in ${ }^{\circ} \mathrm{C}$ ),

$m_{\mathrm{O}}(t)=0.011 t+0.263$

and

$b_{\mathrm{O}}(t)=-(0.135 t+5.006)$.

The temperature $t$ in Eqs. (4) and (5) is usually a mean value of temperature for a series of sampling events, such as annual or monthly mean temperature at each sampling site. After the values of $m_{\mathrm{O}}$ and $b_{\mathrm{O}}$ are calculated using Eqs. (4) and (5), we can use Eq. (2) to calculate the values of $\log K_{\mathrm{P}}$. Since this method can be used to predict the values of $\log K_{\mathrm{P}}$, we use $\log K_{\mathrm{PP}}$ (the second "P" in the subscript $K_{\mathrm{PP}}$ indicates prediction) instead of $K_{\mathrm{PR}}$ in Eq. (2), and rewrite them as

$\log K_{\mathrm{PP}}=m_{\mathrm{O}}(t) \log K_{\mathrm{OA}}+b_{\mathrm{O}}(t)$,

where $m_{\mathrm{O}}(t)$ and $b_{\mathrm{O}}(t)$ are given by Eqs. (4) and (5), respectively. 
It is noteworthy that $\log K_{\mathrm{PP}}$ in Eq. (6) depends on two parameters, temperature $t$ and $K_{\mathrm{OA}}$ (which is also a function of temperature); $K_{\mathrm{OA}}$ is given by the empirical equation (Harner and Shoeib, 2002):

$\log K_{\mathrm{OA}}=A+B /(t+273.15)$,

where $t$ (in ${ }^{\circ} \mathrm{C}$ ) is the temperature for each sampling event, and the parameters $A$ and $B$ are given in Table S1 in the Supplement for several PBDE congeners. It should be borne in mind that temperature $t$ in Eqs. (4) and (5) can also be used as the temperature for each sampling event, and thus using Eq. (7), we can express $\log K_{\mathrm{PP}}$ in Eq. (6) as a function of a single independent variable of $\log K_{\mathrm{OA}}$ as (Li and Jia, 2014)

$\log K_{\mathrm{PP}}\left(K_{\mathrm{OA}}\right)=0.011 B\left(\log K_{\mathrm{OA}}-12.27\right) /$

$\left(\log K_{\mathrm{OA}}-A\right)-2.74 \log K_{\mathrm{OA}}+31.85$.

These two Eqs. (6 and 8) have been successfully applied to predict the values of $K_{\mathrm{P}}$ for PBDEs as functions of $\log K_{\mathrm{OA}}$ in the air of China and other countries in the north temperate zone and also at an Arctic site in East Greenland Sea (Li and Jia, 2014), and our results matched the monitoring data well at background, rural, urban, and suburban sites, but not at e-waste sites due to the unpredictable PBDE emissions at these sites. The results indicated that our new equations have a better performance than Eq. (3) in describing G/P partitioning behavior of PBDEs in air as functions of $\log K_{\mathrm{OA}}$. We also found for the first time that the G/P partitioning of PBDE congeners can reach a maximum value if the ambient temperature is low enough. A criterion to classify the equilibrium and non-equilibrium status for PBDEs was also established using $\log K_{\mathrm{OA}}$ (Li and Jia, 2014).

These equations, however, suffer from two drawbacks. First, these equations are derived at the temperature range of -22 to $+38^{\circ} \mathrm{C}$, and thus cannot be used at temperatures beyond this range; secondly, these equations were obtained empirically, and do not have a strong theoretical foundation. Therefore, in this paper, we study the G/P partitioning behavior of PBDEs in global air in a theoretical way. The objectives of this study are to establish a partitioning model between gaseous and particulate phases for PBDEs, which can reveal the real partitioning mechanism of PBDEs between these two phases, and to predict the partition quotients defined in Eq. (1) accurately for PBDEs in air, thus achieving the capability to address a series of G/P partitioning issues of these chemicals, such as those presented previously (Yang et al., 2013; Li and Jia, 2014).

\section{Theory}

\subsection{Equilibrium state and steady state}

To develop a new model in simulating G/P partitioning behavior, we need to understand the equilibrium state and steady state for SVOCs in environment. The steady state is a state in which no change occurs with time, or all time derivatives are equal to zero. "Equilibrium implies that phases have concentrations such that they experience no tendency for net transfer of mass" (Mackay 2001). These two terms have been frequently mistaken with each other. In the author's book (2001), Mackay gave examples to explain the difference between these two states, indicating a chemical is in equilibrium between two media (phases) as long as its fugacities in the two media (phases) are equal no mater the system is steady or unsteady.

We also noticed that although equilibrium is actually an ideal event since such a system cannot exist in a real environment, this state has been successfully applied in some cases. Good examples are to treat the air-water exchange for the gaseous pesticide $\alpha$-hexachlorocyclohexane ( $\alpha$-HCH) (Jantunen and Bidleman, 1996, 1997; Li et al., 2004) and airsoil exchange for gaseous polychlorinated biphenyls (PCBs) (Li et al., 2010). In these two examples, the factors other than the diffusion due to random molecular movement were negligible, and the systems can be treated as equilibrium; thus, the net flux of gaseous $\alpha-\mathrm{HCH}$ between air and water, and gaseous PCBs between air and soil are zero. We realized, however, that the exchange of SVOCs between the gas and particle phases is different since the advection processes, such as dry and wet depositions, caused by an external force (gravity) on the particles, cannot be ignored in studying the partitioning behavior of SVOCs between these two phases. Therefore, we suggest that the steady state, not equilibrium state, should be applied here.

\subsection{G/P partitioning model under steady state}

\subsubsection{Basic equation}

An equation describing $\mathrm{G} / \mathrm{P}$ partitioning under steady state of PBDEs is

$N_{\mathrm{G}-\mathrm{P}}=N_{\mathrm{P}-\mathrm{G}}+N_{\mathrm{P}-\mathrm{S}}$,

where $N_{\mathrm{G}-\mathrm{P}}$ is flux of PBDEs from gas phase to particle phase, $N_{\mathrm{P}-\mathrm{G}}$ is flux of PBDEs from particle phase to gas phase, and $N_{\mathrm{P}-\mathrm{S}}$ the net flux of particle-bound PBDEs between air and earth surface, such as water body or surface soil. For the sake of simplicity, we only consider dry and wet depositions in $N_{\mathrm{P}-\mathrm{S}}$, which is given by (Mackay 2001)

$N_{\mathrm{P}-\mathrm{S}}=f_{\mathrm{P}}\left(D_{\mathrm{D}}+D_{\mathrm{W}}\right)$,

where $f_{\mathrm{P}}$ is fugacity of particle in air, given by Eq. (S1) in the Supplement with subscript "I" being "P", and $D_{\mathrm{D}}$ is $\mathrm{D}$ value of dry deposition of particle-phase PBDEs described by (Mackay 2001)

$D_{\mathrm{D}}=U_{\mathrm{D}} v_{\mathrm{P}} A Z_{\mathrm{P}}$,

where $U_{\mathrm{D}}$ is dry deposition velocity (a typical value being $10 \mathrm{~m} \mathrm{~h}^{-1}$ ), $A$ is the area between air and earth (water or soil), 
and $Z_{\mathrm{P}}$ is $Z$ value of aerosol, given by Eq. (S3) in the Supplement, and $\nu_{\mathrm{P}}$ is the volume fraction of aerosol, given by

$\nu_{\mathrm{P}}=10^{-9} \mathrm{TSP} / \rho$,

where TSP is the concentration of total suspended particles in air $\left(\mu \mathrm{g} \mathrm{m}^{-3}\right)$ and $\rho$ is the density of the particle $\left(\mathrm{kg} \mathrm{m}^{-3}\right)$. $D_{\mathrm{W}}$ is $D$ value of wet deposition given by (Mackay, 2001)

$D_{\mathrm{W}}=U_{\mathrm{R}} Q v_{\mathrm{P}} A Z_{\mathrm{P}}$,

where $U_{\mathrm{R}}$ is rain rate, a typical value being $0.5\left(\mathrm{~m} \mathrm{yr}^{-1}\right) . Q$ is a scavenging ratio representing the volume of air efficiently scavenged by rain of its particle content, per unit volume of rain. A typical value for $Q$ of 200000 may be used. Substituting the above two equations in Eq. (10) leads to

$N_{\mathrm{P}-\mathrm{S}}=f_{\mathrm{P}}\left(U_{\mathrm{D}}+U_{\mathrm{R}} Q\right) \nu_{\mathrm{P}} A Z_{\mathrm{P}}$

\subsubsection{Gas/particle exchange of PBDEs}

One of the most important issues for investigating the G/P partitioning behavior is the exchange of PBDE between air and particle. We treat each particle as a sphere with a mean diameter of $d$, a volume of $v=\pi d^{3} / 6$, surface area $a=\pi d^{2}$, and a mass $m=\rho v$, where $\rho$ is the density of the particle. The number of particles in $1 \mathrm{~m}^{3}$ of air is $n=\mathrm{TSP} / m$. In air with volume of $A h$ ( $h$ is the height of atmosphere), the total area of the particles is

$A_{\mathrm{P}}=6 \mathrm{TSP}\left(\mathrm{g} \mathrm{m}^{-3}\right) \times A\left(\mathrm{~m}^{2}\right) h(\mathrm{~m}) /\left(\rho\left(\mathrm{g} \mathrm{m}^{-3}\right) d(\mathrm{~m})\right)$.

Assuming $\rho=1.5 \times 10^{6} \mathrm{~g} \mathrm{~m}^{-3}, d=1.0 \times 10^{-7} \mathrm{~m}$ (Rissler et al., 2006) $h=1.0 \times 10^{3} \mathrm{~m}$, the above equation becomes

$A_{\mathrm{P}}=0.04 A \times \mathrm{TSP}$.

To be simplified, we treat the particles as a film, called the particle film, with a thickness of $d$, a surface area of $A_{\mathrm{P}}$, as shown in Fig. S1 in the Supplement. The ratio between $A_{\mathrm{P}}$ and $A$ is

$R_{\mathrm{P}}=A_{\mathrm{P}} / A=0.04 \mathrm{TSP}$,

which is a linear function of TSP.

In order to study the movement of SVOCs between air and particle, we adapted the method used for the air-soil interface introduced by Mackay (2001). For diffusion, the tworesistance approach is used, and the overall $D$ values is given by

$1 / D_{\mathrm{V}}=1 / D_{\mathrm{E}}+1 /\left(D_{\mathrm{A}}+D_{\mathrm{H}}\right)$,

where $D_{\mathrm{E}}$ is air boundary layer $D$ value, $D_{\mathrm{A}}$ and $D_{\mathrm{H}}$ are diffusion $D$ values of chemical in air and water sub-phases in particle film, respectively. $D_{\mathrm{E}}$ is deduced as the product of the surface area of the particle film, $A_{\mathrm{P}}\left(\mathrm{m}^{2}\right)$, a mass transfer coefficient $k_{\mathrm{V}}\left(\mathrm{mh}^{-1}\right)$, and the $Z$ value of air $Z_{\mathrm{G}}$, given by

$D_{\mathrm{E}}=A_{\mathrm{P}} k_{\mathrm{V}} Z_{\mathrm{G}}$.
Here,

$k_{\mathrm{V}}=B_{\mathrm{a}} / l_{\mathrm{a}}$,

where $B_{\mathrm{a}}$ is the chemical's molecular diffusivity in air $\left(0.018 \mathrm{~m}^{2} \mathrm{~h}^{-1}\right.$ was assumed $)$, and $l_{\mathrm{a}}$ is an air boundary layer thickness (0.00475 $\mathrm{m}$ was assumed) (Mackay 2001).

In comparison to the soil surface in air-soil exchange, the particle film that we suggested in our model keeps moving within the atmosphere and thus has much more chances to intersect with the chemical in gas phase. Therefore, the mass transfer coefficient will be larger than that given by Eq. (20), and accordingly, a parameter $C$ is introduced in Eq. (20), leading to

$k_{\mathrm{V}}=C B_{\mathrm{a}} / l_{\mathrm{a}}$.

Thus, the term $C B_{\mathrm{a}}$ is the chemical's molecular diffusivity for the particle film in air, and its value will be determined later.

Since most of the SVOCs (including PBDEs) are associated with the organic matter of the particles, again for the sake of simplicity, the two terms, $D_{\mathrm{A}}$ and $D_{\mathrm{H}}$, in Eq. (18) are neglected, which becomes

$D_{\mathrm{V}}=D_{\mathrm{E}}=A_{\mathrm{P}} k_{\mathrm{V}} Z_{\mathrm{G}}$

The flux of PBDEs from gas phase to particle phase, $N_{\mathrm{G}-\mathrm{P}}$, becomes

$N_{\mathrm{G}-\mathrm{P}}=f_{\mathrm{G}} D_{\mathrm{E}}$,

and the flux from particle phase to gas phase, $N_{\mathrm{P}-\mathrm{G}}$, is

$N_{\mathrm{P}-\mathrm{G}}=f_{\mathrm{P}} D_{\mathrm{E}}$

If the term $N_{\mathrm{P}-\mathrm{S}}$ is dropped from Eq. (9), i.e., the net flux of particle-bound PBDEs between air and surface is neglected, we will have

$N_{\mathrm{G}-\mathrm{P}}=N_{\mathrm{P}-\mathrm{G}}$.

From Eqs. (23) and (24), the fugacities of a chemical in gas phase $\left(f_{\mathrm{G}}\right)$ and in particle phase $\left(f_{P}\right)$ are equal, and thus the steady state becomes equilibrium. Therefore, it is concluded that equilibrium is just a special case of steady state when $N_{\text {P-S }}$ is ignored.

\subsection{G/P equations under steady state}

\subsubsection{G/P partition coefficient under steady state}

We use Eqs. (10), (23), and (24) into Eq. (9), leading to

$f_{\mathrm{p}}\left(D_{\mathrm{E}}+D_{\mathrm{D}}+D_{\mathrm{W}}\right)=f_{\mathrm{G}} D_{\mathrm{E}}$ 
By using Eqs. (S6) and (S7) in the Supplement, the above equation leads to

$C_{\mathrm{p}}^{\prime} / C_{\mathrm{G}}=\left(Z_{\mathrm{P}} / Z_{\mathrm{G}}\right)\left(D_{\mathrm{E}} /\right.$

$\left.\left(D_{\mathrm{E}}+D_{\mathrm{D}}+D_{\mathrm{W}}\right)\right)=K_{\mathrm{PG}}\left(1 /\left[1+\left(D_{\mathrm{D}}+D_{\mathrm{W}}\right) / D_{\mathrm{E}}\right]\right)$,

where $C_{\mathrm{P}}^{\prime}\left(\mathrm{pg} \mathrm{m}^{-3}\right.$ of particle $)$ and $C_{\mathrm{G}}\left(\mathrm{pg} \mathrm{m}^{-3}\right.$ of air $)$ are concentrations of SVOCs in particle and gas phases, respectively, and $K_{\mathrm{PG}}$ is dimensionless G/P partition coefficient under equilibrium $\left(=Z_{\mathrm{P}} / Z_{\mathrm{G}}\right)$. Setting parameter $\alpha$ as

$\alpha=1 /\left[1+\left(D_{\mathrm{D}}+D_{\mathrm{W}}\right) / D_{\mathrm{E}}\right]$,

and the above equation becomes

$C_{p}^{\prime} / C_{\mathrm{G}}=\alpha K_{\mathrm{PG}} \quad$ (at steady state).

By using Eqs. (S10) and (S11), $C_{\mathrm{p}}^{\prime}$ and $K_{\mathrm{PG}}$ are replaced by $C_{\mathrm{p}}$ and $K_{\mathrm{PE}}$, respectively, and Eq. (28) becomes

$\left(C_{\mathrm{P}} / \mathrm{TSP}\right) / C_{\mathrm{G}}=\alpha K_{\mathrm{PE}}$.

Defining a G/P partition coefficient under steady state,

$K_{\mathrm{PS}}=\left(C_{\mathrm{P}} / \mathrm{TSP}\right) / C_{\mathrm{G}} \quad($ at steady state $)$,

where $C_{\mathrm{G}}$ and $C_{\mathrm{P}}$ are concentrations of PBDEs in gas and particle phases (both in $\mathrm{pg} \mathrm{m}^{-3}$ of air), respectively, at steady state, and the subscript " $\mathrm{S}$ " in $K_{\mathrm{PS}}$ indicates steady state. Although Eq. (30) seems the same as Eq. (1) (for $K_{\mathrm{P}}$ ) and Eq. (S8) (for $K_{\mathrm{PE}}$ ), they are different since Eq. (30) is defined under steady state, Eq. (S8) is under equilibrium, and Eq. (1) was defined at neither steady nor equilibrium state. Thus, Eq. (29) becomes

$\log K_{\mathrm{PS}}=\log K_{\mathrm{PE}}+\log \alpha$.

In the above equation, $\log K_{\mathrm{PE}}$ is designated the equilibrium term, given by Eq. (3), and $\log \alpha$ is the non-equilibrium term. Therefore, we have two predicted partition coefficients: partition coefficient $K_{\mathrm{PS}}$ under steady state when the system is at steady state, and partition coefficient $K_{\mathrm{PE}}$ under equilibrium when the system is at equilibrium. Equation (31) indicates that the equilibrium is just a special case of the steady state when $\log \alpha=0$.

\subsubsection{Non-equilibrium term $\log \alpha$}

In Eq. (27), setting

$G=C\left(D_{\mathrm{D}}+D_{\mathrm{W}}\right) / D_{\mathrm{E}}$,

Eq. (27) becomes

$\alpha=1 /(1+G / C)$

or

$\log \alpha=-\log (1+G / C)$.

Substituting Eqs. (11), (13) and (19) in Eq. (32), which leads after some manipulations to

$G=2.09 \times 10^{-10} f_{\mathrm{OM}} K_{\mathrm{OA}}$.

Thus, as in $K_{\mathrm{PE}}, \log \alpha$ is also a function of $f_{\mathrm{OM}}$ and $K_{\mathrm{OA}}$.

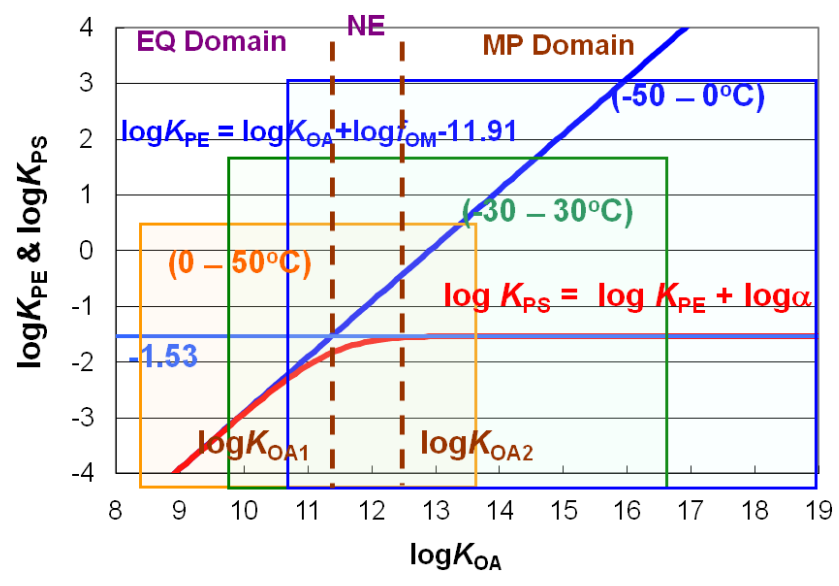

Figure 1. Variation of $\log K_{\mathrm{PE}}$ and $\log K_{\mathrm{PS}}$ as functions of $\log K_{\mathrm{OA}}$ with a temperature range of -50 to $+50^{\circ} \mathrm{C}$. Two threshold values of $\log K_{\mathrm{OA}}\left(\log K_{\mathrm{OA} 1}\right.$ and $\left.\log K_{\mathrm{OA} 2}\right)$ are also shown, which divide the space of $\log K_{\mathrm{OA}}$ into three domains: the equilibrium (EQ), the non-equilibrium (NE), and the maximum partition (MP) domains. The three squares designate the $\log K_{\mathrm{P}}-\log K_{\mathrm{OA}}$ graphs with three different temperature ranges: 0 to $+50^{\circ} \mathrm{C},-30$ to $+30^{\circ} \mathrm{C}$, and -50 to $0^{\circ} \mathrm{C}$, representing the tropical and subtropical climate zones, warm temperate climate zone, and boreal and tundra climate zones, respectively.

\subsection{3 $\log \alpha$ as functions of $\log K_{\mathrm{OA}}$ and temperature}

Figure S2 in the Supplement depicts variations of $\log \alpha$ as functions of $\log K_{\mathrm{OA}}$ and temperature $t$ with $C=5$. As shown in Fig. S2A, the function of $\log \alpha$ versus $\log K_{\mathrm{OA}}$ is a curve shared by all PBDE congeners, showing that when $\log K_{\mathrm{OA}}<\sim 10.4, \log \alpha=0$, the state is equilibrium. In contrast with the function of $\log \alpha$ versus $\log K_{\mathrm{OA}}$, the functions of $\log \alpha$ versus $t$ are different for different PBDE congeners, as shown in Fig. S2B in the Supplement. This figure explains why light PBDE congeners, such as BDE-17 and -28, can reach equilibrium state much more easily than heavy PBDE congeners. It is obvious from Fig. S2B that the curves of BDE-17 and -28 deviate significantly from zero at a low temperature $\left(\sim-10^{\circ} \mathrm{C}\right)$, indicating that the values of $\log \alpha$ are equal or close to 0 at a wide range of environmental temperature $\left(t>-10^{\circ} \mathrm{C}\right)$. For highly brominated congeners, BDE153 for example, the values of $\log \alpha$ deviates significantly from zero even when $t<+40^{\circ} \mathrm{C}$, causing the equilibrium state to be at a much narrower ambient temperature range for this chemical $\left(t>+40^{\circ} \mathrm{C}\right)$ than BDE-17 and -28 .

\subsection{Threshold values of $\log \mathrm{K}_{\mathrm{OA}}$ and temperature}

Since all the equations to calculate the parameter $K_{\mathrm{PE}}$ and $K_{\mathrm{PS}}$ link only the PBDE parameter $\log K_{\mathrm{OA}}$, it may be advantageous to explore partitioning behavior according to $\log K_{\mathrm{OA}}$, rather than individual $\mathrm{PBDE}$ congeners or homolog groups. Under this consideration, we drew $\log K_{\mathrm{PS}}-$ $\log K_{\mathrm{OA}}$ and $\log K_{\mathrm{PE}}-\log K_{\mathrm{OA}}$ graphs for all PBDE con- 
geners/homologues at an environmental temperature range of -50 to $+50{ }^{\circ} \mathrm{C}$, as shown in Fig. 1. The straight line (thick blue) for $\log K_{\mathrm{PE}}$ and the curve (red) for $\log K_{\mathrm{PS}}$ can be used for all PBDE congeners/homologues as long as their ranges of $\log K_{\mathrm{OA}}$ are known. Of course, it should be mentioned that the different PBDE congeners have different ranges of $\log K_{\mathrm{OA}}$ at the same temperature span, and thus are represented by different portions of the curves in the Fig. 1, accordingly showing different $\mathrm{G} / \mathrm{P}$ partitioning behaviors.

There are three cases for $G$ in Eq. (33b).

(1) $G \ll C\left(D_{\mathrm{D}}+D_{\mathrm{W}} \ll D_{\mathrm{E}}\right)$

In this case, Eq. (33b) becomes

$\log \alpha=-\log (1+G / C) \approx 0$,

which is equilibrium state.

(2) $G=C\left(D_{\mathrm{D}}+D_{\mathrm{W}}=D_{\mathrm{E}}\right)$

In this case, Eq. (33b) becomes

$\log \alpha=-\log 2$.

If we assume that $f_{\mathrm{OM}}=0.1$ and $C=5$, then we have the first threshold value from Eqs. (33b) and (34),

$\log K_{\mathrm{OA} 1}=11.4$,

which is very close to the threshold value of $\log K_{\mathrm{OA}}=$ 11.5 suggested by Li and Jia (2014). The physical meaning of $\log K_{\mathrm{OA} 1}$ is, at this threshold, the data of $\log K_{\mathrm{PS}}$ deviates from $\log K_{\mathrm{PE}}$ by an amount of $\log 2$.

(3) $G \gg C\left(D_{\mathrm{D}}+D_{\mathrm{W}} \gg D_{\mathrm{E}}\right)$

In this case, Eq. (33b) becomes

$\log \alpha \approx-\log (G / C)=\log C-\log K_{\mathrm{PE}}-2.23$,

thus $\log K_{\mathrm{PS}}$ in Eq. (31) reaches its maximum value,

$\log K_{\mathrm{PSM}}=-1.53$ or $K_{\mathrm{PSM}}=0.03$,

when $G \gg C$. This is very close to the maximum value of -1.5 suggested by Li and Jia (2014).

The maximum value of $\log K_{\mathrm{PS}}$ is clearly shown in Fig. 1 (the thin blue horizontal line), and we define the second threshold value as

$\log K_{\mathrm{OA} 2}=12.5$.

As shown in Fig. 1, the first threshold value of $\log K_{\mathrm{OA}}$ divides the whole range of $\log K_{\mathrm{OA}}$ into equilibrium (EQ) and non-equilibrium (NE) domains. The second threshold indicates the start of the maximum partition (MP)domain, in which the values of $\log K_{\mathrm{PS}}$ reach a maximum value of $\log K_{\mathrm{PSM}}$, which is independent of the values of $f_{\mathrm{OM}}$ and $K_{\mathrm{OA}}$.

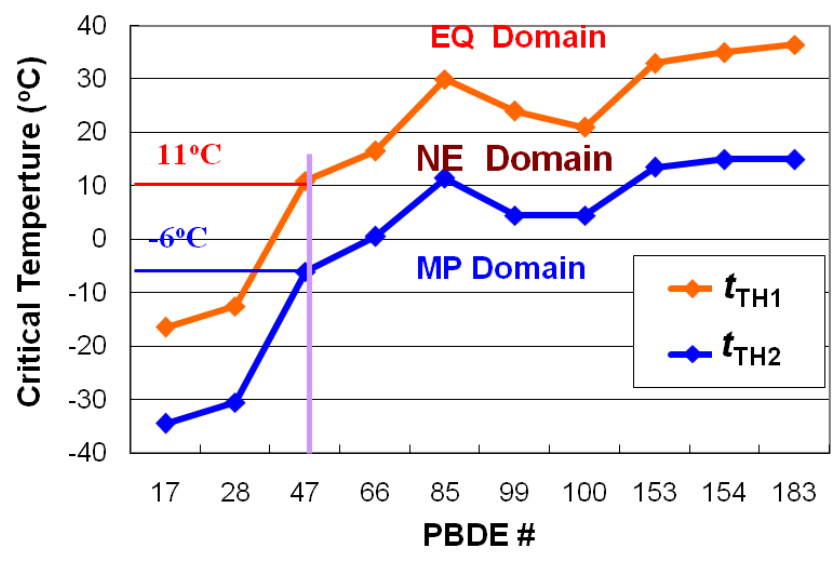

Figure 2. The first and second threshold temperatures, $t_{\mathrm{TH} 1}$ and $t_{\mathrm{TH} 2}$ for 10 PBDE congeners, which divide the temperature space into the same three domains (EQ, NE, and MP).

In brief, as shown in Fig. 1, the curve of $\log K_{\mathrm{PS}}$, originally coinciding with the straight line of $\log K_{\mathrm{PE}}$, increases along with increase of $\log K_{\mathrm{OA}}$, and separates visibly (by a mount of $\log 2$ ) from the straight line of $\log K_{\mathrm{PE}}$ at the first threshold value of $\log K_{\mathrm{OA} 1}$, entering the NE domain from the EQ domain. After the second threshold value of $\log K_{\mathrm{OA} 2}$, the curve of $\log K_{\text {PS }}$ enters the MP domain and becomes a horizontal straight line of $\log K_{\mathrm{PS}}=-1.53$.

The values of $\log K_{\mathrm{OA}}$ depend on each PBDE congener and the ambient temperature, as discussed previously (Harner and Shoeib, 2002). Accordingly, we defined two threshold values for temperature, the threshold temperatures $t_{\mathrm{TH} 1}$ and $t_{\mathrm{TH} 2}$ which are the temperatures when $\log K_{\mathrm{OA}}$ of PBDE congeners equals the threshold values $\log K_{\mathrm{OA} 1}$ and $\log K_{\mathrm{OA} 2}$, respectively. As presented in Fig. 2, while the threshold values of $\log K_{\mathrm{OA} 1}$ and $\log K_{\mathrm{OA} 2}$ are constants for all congeners, the threshold values for $t_{\mathrm{TH} 1}$ and $t_{\mathrm{TH} 2}$ are different for different PBDE congeners. These two threshold temperature values divided the temperature space also into the same three domains; the EQ domain when $t>t_{\mathrm{TH} 1}$, the NE domain when $t \leq t_{\mathrm{TH} 1}$, and the MP domain when $t \leq t_{\mathrm{TH} 2}$. Taking BDE-47 as an example, with its $t_{\mathrm{TH} 1}=+11^{\circ} \mathrm{C}$ and $t_{\mathrm{TH} 2}=-6^{\circ} \mathrm{C}$, BDE-47 is in the EQ domain when $t>+11^{\circ} \mathrm{C}$; in the $\mathrm{NE}$ domain when $t \leq+11^{\circ} \mathrm{C}$; and in the MP domain at $t \leq-6^{\circ} \mathrm{C}$.

\subsection{Particle-phase fraction}

Another important parameter, the fraction of chemical in the particle phase, $\phi\left(=C_{\mathrm{P}} /\left(C_{\mathrm{G}}+C_{\mathrm{P}}\right)\right)$, can be calculated from $K_{\mathrm{P}}$ as

$\phi_{\mathrm{PX}}=K_{\mathrm{PX}} \mathrm{TSP} /\left(1+K_{\mathrm{PX}} \mathrm{TSP}\right)$

where the subscript "PX" can be one of "PS", "PE", and "PR". Thus, the maximum value of particle-phase fraction 
can be obtained from Eqs. (39) and (41) as

$\phi_{\mathrm{PSM}}=0.03 \mathrm{TSP} /(1+0.03 \mathrm{TSP})$

which indicates that while the maximum partition coefficient $\log K_{\text {PSM }}$ is a constant for all PBDE congeners, its corresponding maximum value of particle-phase fraction is not, but it depends on TSP. The variation of $\phi_{\text {PSM }}$ as a function of TSP is depicted in Fig. S3 in the Supplement.

\section{Application of the equations}

\subsection{G/P partitioning of PBDEs in Chinese air from China-SAMP-II}

In the previous section, we derived Eq. (31) to predict the values of partition coefficient under steady state $K_{\mathrm{PS}}$. In this subsection, we used these equations to predict $K_{\mathrm{P}}$ for air samples collected at 15 sites across China under our PBDE monitoring program, China-SAMP-II (Yang et al., 2013, Li and Jia, 2014), and the results is later compared with the predicted values of partition coefficient under equilibrium state $K_{\mathrm{PE}}$, obtained using Eq. (3); and the values of partition quotient, $K_{\mathrm{PR}}$, obtained using Eq. (2) with the help of $K_{\mathrm{PM}}$, calculated from Eq. (1) using the monitoring data $C_{\mathrm{P}}$ and $C_{\mathrm{G}}$. Among the three modeled values ( $K_{\mathrm{PS}}, K_{\mathrm{PE}}$, and $K_{\mathrm{PR}}$ ), $K_{\mathrm{PR}}$ values are the ones closest to the values of $K_{\mathrm{PM}}$ since $\log K_{\mathrm{PR}}$ values are obtained directly from $\log K_{\mathrm{PM}}$ by least squares regression against $\log K_{\mathrm{OA}}$, and the accuracy of the equations of $K_{\mathrm{PS}}$ and $K_{\mathrm{PE}}$ depends on how close their results are to those given by $K_{\mathrm{PR}}$.

Figures S4 and S5 in the Supplement depict the variations of $\log K_{\mathrm{PS}}, \log K_{\mathrm{PE}}$, and $\log K_{\mathrm{PR}}$ as functions of $\log K_{\mathrm{OA}}$ for the 15 sampling sites and 10 PBDE congeners, respectively, both showing the curve of $\log K_{\mathrm{PS}}$ is closer to the regression line of $\log K_{\mathrm{PR}}$ than $\log K_{\mathrm{PE}}$. It is worthwhile to point out that for the best match between the results of $\log K_{\mathrm{PS}}$ and $\log K_{\mathrm{PR}}$ for PBDEs, $C=5$ was used in Eq. (5) to calculate $\log K_{\mathrm{PS}}$ in air at all the sampling sites with an exception of the site of Waliguan, where $C=50$ was used. The reason why a much higher value of $C$ was used at this site will be explained later. Figure S5 also shows that, from the light PBDE congeners to the heavy ones, the ranges of $\log K_{\mathrm{OA}}$ for each PBDE congeners (at temperature range of $-22^{\circ} \mathrm{C}-+38^{\circ} \mathrm{C}$ ) move from left to right, from values smaller than $\log K_{\mathrm{OA} 1}$ for BDE-17 to larger than $\log K_{\mathrm{OA} 1}$ for BDE-183, or the states that these congeners reside in change from EQ domain to the NE domain, and finally reach the MP domain.

The 10 regression lines $\left(\log K_{\mathrm{PR}}\right)$ for the 10 PBDE congeners shown in Fig. S5 are all presented in Fig. S6 in the Supplement along with the curves of $\log K_{\mathrm{PE}}$ and $\log K_{\mathrm{PS}}$, indicating evidently that these 10 lines of $\log K_{\mathrm{PR}}$ change their slopes $m_{\mathrm{O}}$ along the curve of $\log K_{\mathrm{PS}}$, not the straight line of $\log K_{\mathrm{PE}}$, and accordingly, the curve of $\log K_{\mathrm{PS}}$ matches the monitored G/P partitioning data very well for all the 10 PBDE congeners in Chinese air.

We understand that modelers are most interested in $K_{\mathrm{P}}$ values as a function of temperature for each PBDE congener. Figure $\mathrm{S} 7$ in the Supplement presents variations of $\log K_{\mathrm{PS}}$, $\log K_{\mathrm{PE}}$, and $\log K_{\mathrm{PR}}$ as functions of temperature for the 10 PBDE congeners, indicating that the curve of $\log K_{\mathrm{PS}}$ matches the line of $\log K_{\mathrm{PR}}$ for each PBDE congener dramatically well, particularly for the highly brominated congeners. It is interesting to note that the two threshold temperatures, $t_{\mathrm{TH} 1}$ and $t_{\mathrm{TH} 2}$, designated by two vertical dashed lines, increase from the less brominated to highly brominated PBDEs. For example, the value of $t_{\mathrm{TH} 1}$ of BDE-17 equals $-16.5^{\circ} \mathrm{C}$, meaning that this compound is in the EQ domain in the most ambient temperature range of $\geq-16.5^{\circ} \mathrm{C}$, while for BDE- $183, t_{\mathrm{TH} 1}=36.5^{\circ} \mathrm{C}$ and $t_{\mathrm{TH} 2}=15^{\circ} \mathrm{C}$, meaning that this compound is in the $\mathrm{EQ}$ domain only when $t>36.5^{\circ} \mathrm{C}$, in the NE domain when $t \leq 36.5^{\circ} \mathrm{C}$, and in the MP domain when $t \leq 15.0^{\circ} \mathrm{C}$. We also calculated the modeled values of $\log K_{\mathrm{PS}}$ for five typical PBDE congeners as functions of temperature from -50 to $+50^{\circ} \mathrm{C}$, and the results are given in Fig. S8 in the Supplement, showing that, along with a decrease of temperature, the values of $\log K_{\mathrm{PS}}$ for PBDE congeners increase to a maximum partition value; the more highly brominated the congener is, the higher is the value of its first threshold temperature $\left(t_{\mathrm{TH} 1}\right.$, data are not shown), second threshold temperature $\left(t_{\mathrm{TH} 2}\right)$, and thus higher temperatures at which the congener reaches the NE and MP domains.

As shown in Fig. 1, the partitioning behavior of PBDEs depends on ambient temperature of sampling events. There are three squares presented in Fig. 1 indicating the three regions with different temperature ranges, 0 to $+50^{\circ} \mathrm{C}$ (orange), -30 to $+30^{\circ} \mathrm{C}$ (green), and -50 to $0{ }^{\circ} \mathrm{C}$ (blue). Here, we take the two sampling sites from China-SAMP-II (Yang et al., 2013; $\mathrm{Li}$ and Jia, 2014). One is Harbin in the northeast of China, with a sampling temperature range of -22 to $+28^{\circ} \mathrm{C}$, within the green square, and the other is Guangzhou in the south of China, with a range of +8 to $+38^{\circ} \mathrm{C}$, within the orange square, as examples to show how the threshold values can be used in study the G/P partitioning behavior of PBDEs.

We determined the ranges of $\log K_{\mathrm{OA}}$ for the 10 PBDEs at the site of Harbin (vertical bars) based on the ambient temperature range of -22 to $+28^{\circ} \mathrm{C}$ at the site, and the results are presented in Fig. 3. The two threshold values of $\log K_{\mathrm{OA}}, \log K_{\mathrm{OA} 1}$ and $\log K_{\mathrm{OA} 2}$ (the horizontal light blue dashed lines), divide the space of $\log K_{\mathrm{OA}}$ (the left axis) into three domains, the EQ, the NE, and the MP domains, and accordingly, the 10 PBDEs in Harbin air can be segregated into three groups; BDE-17 and 28 (3-Br homologue) as equilibrium EQ group, BDE-47 and 66 (4-Br homologue) as semi-equilibrium SE group, and others (>4-Br homologues) as non-equilibrium NE group. The dominant portions of $\log K_{\mathrm{OA}}$ for the EQ group (purple lines) are under the line of $\log K_{\mathrm{OA} 1}$, i.e., these congeners are mainly in the EQ do- 


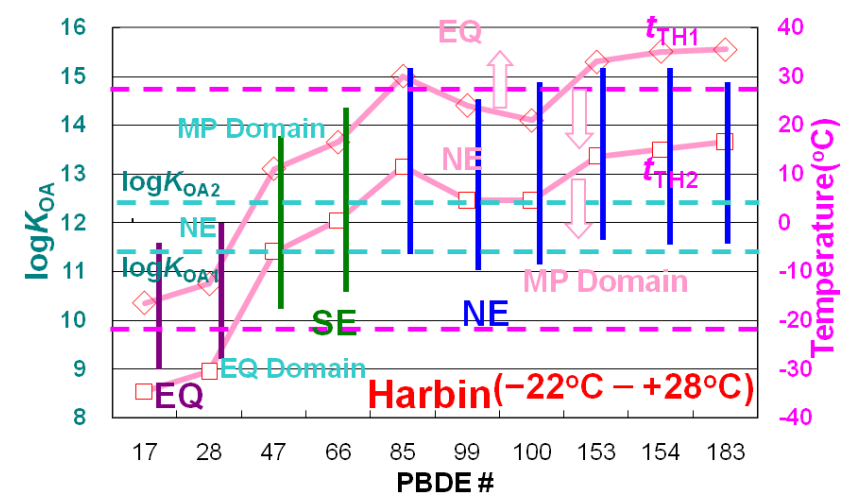

Figure 3. The range of $\log K_{\mathrm{OA}}$ (the left axis) and the threshold temperatures (the right axis) for $10 \mathrm{PBDE}$ congeners in Harbin air at a temperature range of -22 to $+28^{\circ} \mathrm{C}$. The ranges of $\log K_{\mathrm{OA}}$ for the 10 PBDE congeners are given by the vertical bars. The two horizontal light blue dashed lines give the two threshold values of $\log K_{\mathrm{OA} 1}$ and $\log K_{\mathrm{OA} 2}$, and the red diamonds and red squares present, respectively, the two corresponding threshold temperatures, $t_{\mathrm{TH} 1}$ and $t_{\mathrm{TH} 2}$. The former divides the space of $\log K_{\mathrm{OA}}$ (the left axis) and the latter divides the temperature space (the right axis) into three domains: the EQ domain, the NE domain, and the MP domain. Thus, the PBDE congeners (homologues) in Harbin air can be segregated into three groups; BDE-17 and -28 (3-Br homologue) as equilibrium EQ group, BDE-47 and -66 (4-Br homologue) as semi-equilibrium SE group, and others ( $>4-\mathrm{Br}$ homologues) as nonequilibrium NE group.

main, while the dominant or whole portions of the NE group (blue lines) are above the line of $\log K_{\mathrm{OA} 1}$, indicating that these congeners are in the NE and the MP domains. The SE group (green lines) is in both the EQ and the NE domains. It is noteworthy that the major portions of $\log K_{\mathrm{OA}}$ for the PBDE congeners in the NE group were in the MP domain. These three domains can also be identified in the temperature space. In Fig. 3, the two threshold temperatures, $t_{\mathrm{TH} 1}$ (the red diamonds) and $t_{\mathrm{TH} 2}$ (the red square), are also shown (the right axis), which is similar to Fig. 2. In the real ambient temperature range, formed by the two red dashed lines $\left(-22^{\circ} \mathrm{C}\right.$ and $\left.+28^{\circ} \mathrm{C}\right)$ at the Harbin site, the major temperature portions of PBDEs in the EQ group were in the EQ domain $\left(t<t_{\mathrm{TH} 1}\right)$, those of the NE group in the NE and MP domains $\left(t \geq t_{\mathrm{TH} 1}\right)$, and those of the SE group in both the EQ and NE domains.

Figure 4 presents the $\log K_{\mathrm{P}}-\log K_{\mathrm{OA}}$ graph for the $10 \mathrm{~PB}$ DEs in Harbin, which is almost identical to the one contained in the green square of Fig. 1. The ranges of $\log K_{\mathrm{OA}}$ for the three groups and their corresponding $\log K_{\mathrm{P}}-\log K_{\mathrm{OA}}$ diagram are also shown. For example, the $\log K_{\mathrm{P}}-\log K_{\mathrm{OA}}$ diagram for the EQ group (3-Br homologue), bound by the two burgundy dashed lines, is mainly in the EQ domain, with a small portion in the $\mathrm{NE}$ domain; the $\log K_{\mathrm{P}}-\log K_{\mathrm{OA}}$ diagram for the SE group (4-Br homologue), contained by two green dashed lines, is mainly in the NE domain, with a small por-

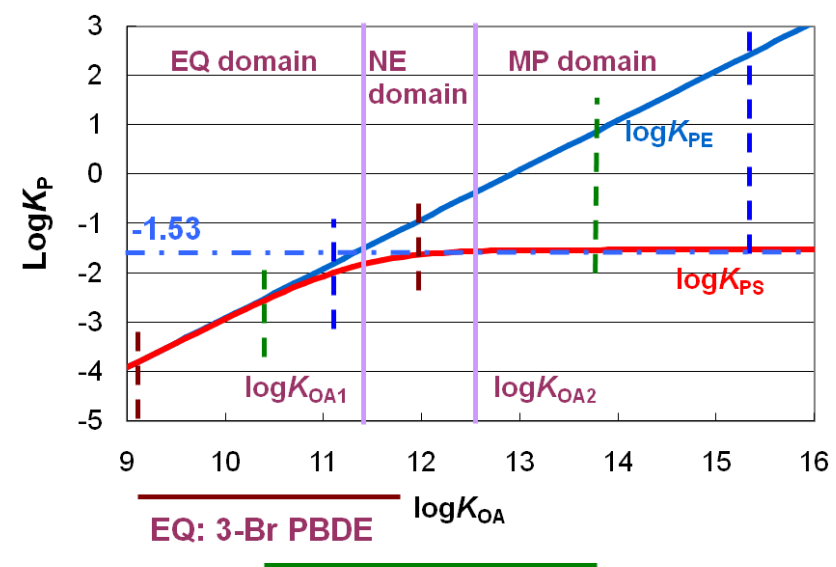

Harbin SE: 4-Br PBDE
$\left(-22^{\circ} \mathrm{C}-+28^{\circ} \mathrm{C}\right)$

Figure 4. The $\log K_{\mathrm{P}}-\log K_{\mathrm{OA}}$ diagram for the $10 \mathrm{PBDE}$ congeners in Harbin air at a temperature range of -22 to $+28^{\circ} \mathrm{C}$. The EQ group includes BDE-17 and -28, the SE group contains BDE-47 and -66 , and the rest belong to NE group. The range of $\log K_{\mathrm{OA}}$ for each group and their corresponding $\log K_{\mathrm{P}}-\log K_{\mathrm{OA}}$ diagram are also shown. The $\log K_{\mathrm{P}}-\log K_{\mathrm{OA}}$ diagram for the EQ group, indicated by two burgundy dashed lines, is mainly in the EQ domain, with a small portion in $\mathrm{NE}$ domain; the $\log K_{\mathrm{P}}-\log K_{\mathrm{OA}}$ diagram for the SE group, contained by two green dashed lines, is mainly in the NE domain, with a small portion in MP domain; and the $\log K_{\mathrm{P}}-$ $\log K_{\mathrm{OA}}$ diagram for the NE group, formed by the two blue dashed lines, is mainly in the NE and MP domains.

tion in the MP domain; and the $\log K_{\mathrm{P}}-\log K_{\mathrm{OA}}$ diagram for the NE group ( $>4-\mathrm{Br}$ homologue), formed by the two blue dashed lines, is mainly in the NE and MP domains.

Similar analysis was carried out for the 10 PBDEs at the site of Guangzhou at an ambient temperature range of +8 to $+38^{\circ} \mathrm{C}$ at the site (Yang et al., 2013), and the results are presented in Figs. S9 and S10 in the Supplement. The 10 PBDEs at Guangzhou air can also be segregated into three groups, BDE-17, -28, and -47 as EQ group, BDE-66, 99, and 100 as SE group, and the others, BDE-85, -99, -100, and 183 as NE group, which are quite different from those for Harbin, caused by the different ambient temperature ranges at the two sites.

We concluded that the PBDEs in Chinese air at 15 sampling sites across China were in the steady state instead of equilibrium state, by realizing that, for less-brominated PBDE congeners, BDE-17 and -28, this steady state can be treated as equilibrium state since their non-equilibrium term $(\log \alpha)$ can be ignored in comparison to the equilibrium term $\left(\log K_{P E}\right)$ in the temperature range of $-22^{\circ} \mathrm{C}$ to $+38^{\circ} \mathrm{C}$ (see Fig. S2B). 


\subsection{G/P partitioning of PBDEs in air from other sources}

There are only a few data available in the literature that we can compare to our prediction data.

We predicted the partitioning behavior of gaseous- and particle-bound PBDEs in the atmosphere at an e-waste site and a rural site in southern China during 2007-2008 using the information given by Tian et al. (2011). We calculated the values of $\log K_{\mathrm{PS}}, \log K_{\mathrm{PE}}$, and $\log K_{\mathrm{PR}}$ as functions of $\log K_{\mathrm{OA}}$, and the results are presented in Fig. S11. It is noticeable that our predicted results are obviously better than those obtained by the equilibrium model at the rural site, but not at the e-waste site, where the data from equilibrium model matched the monitoring data better than those predicted using our equation. This seemed unexpected but could possibly be explained by the fact that the emissions of PBDEs from the e-waste site compensated the flux of PBDEs due to dry and wet deposition, leading a situation that seemed to be at equilibrium. We cannot, however, accept the point of view that the PBDEs in air at the rural area cannot reach equilibrium, but those in air at the e-waste sites can.

The G/P partitioning behavior was studied for seven PBDEs (BDE-28, -47, -99, -100, -153,-154 and -209) at four sites (one suburban, two urban, and one industrial) in Izmir, Turkey, in summer and winter in 2004-2005 with a temperature range of $1.8-22.4^{\circ} \mathrm{C}$ (Cetin and Odabasi, 2007). We calculated the particle-phase PBDE fractions $\phi_{\mathrm{PS}}$ and $\phi_{\mathrm{PE}}$ using Eq. (41) and compared them with the monitoring data, and the results are depicted in Fig. S12. It was noted by the authors that their monitoring data were much lower than the predicted values by the equilibrium equation $\left(\phi_{\mathrm{PE}}\right)$ (Cetin and Odabasi, 2007), but it is obvious that their results matched our predicted data ( $\left.\phi_{\mathrm{PS}}\right)$ very well, among which the best agreement was observed for BDE-209, the most highly brominated congener of PBDEs.

We calculated the G/P partition coefficients for PBDEs in atmosphere of Kyoto, Japan, which were measured in August 2000, and January and September 2001 (Hayakawa et al., 2004), and the variations of $\log K_{\mathrm{PE}}$ and $\log K_{\mathrm{PS}}$ as functions of $\log K_{\mathrm{OA}}$ are presented in Fig. S13, indicating obviously that the values of $\log K_{\mathrm{PS}}$ were in a better agreement with the monitoring data than $\log K_{\mathrm{PE}}$.

Air samples were collected from one urban, one remote, and two rural sites near the Great Lakes in 1997-1999 as part of the Integrated Atmospheric Deposition Network (IADN), among which, those taken when the ambient atmospheric temperatures were $20 \pm 3^{\circ} \mathrm{C}$ were analyzed for the G/P partitioning behavior of PBDEs, and the $\log -\log$ relationship of $K_{\mathrm{P}}$ and their sub-cooled liquid vapor pressures $\left(P_{\mathrm{L}}\right)$ for BDE-47, -99, -100, -153, and -154 were calculated (Strandberg et al., 2001). By using these data, we calculated both $\log K_{\mathrm{P}}$ and $\varphi_{P}$ as functions of $\log K_{\mathrm{OA}}$ for the same five PBDE congeners, using the values of $f_{\mathrm{OM}}=0.2$ and TSP $=25 \mu \mathrm{g} \mathrm{m}^{-3}$ suggested by Harner and Shoeib (2002), which

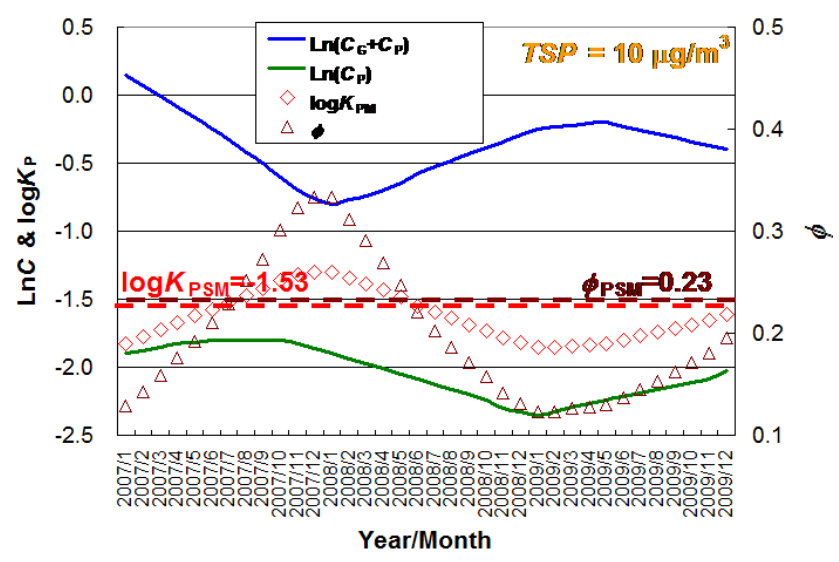

Figure 5. The temporal trends of concentrations of BDE-209 in the Arctic air in gas and particle phases (blue line) and in particle phase (green line) at Alert, Canada from 2007 to 2009 (NCP 2013). The purple triangles and red diamonds are the values of $\varphi$ and $\log K_{\mathrm{P}}$ of BDE-209, respectively, calculated using the concentration data, and match well the values of $\phi_{\mathrm{PSM}}(=0.23)$ and $\log K_{\mathrm{PSM}}(-1.53)$, respectively (TSP $=10 \mu \mathrm{g} \mathrm{m}^{-3}$ was assumed).

are presented in Fig. S14, along with the predicted results under equilibrium state and steady state. Again the results indicated that the prediction by our new equation is more accurate than those by the equilibrium equation.

\subsection{G/P partitioning of PBDEs in the Arctic air}

As discussed in the previous sections, each PBDE congener will reach the maximum partition domain when $\log K_{\mathrm{OA}} \geq$ $\log K_{\mathrm{OA} 2}$ or $t \leq t_{\mathrm{TH} 2}$. The value of $t_{\mathrm{TH} 2}$ of BDE- 183 is $15^{\circ} \mathrm{C}$, meaning that BDE-183 in air will be in MP domain when $t<15^{\circ} \mathrm{C}$. The value of $t_{\mathrm{TH} 2}$ for BDE-209 should be higher $\left(\log K_{\mathrm{OA}}=14.98\right.$ for BDE-209 was estimated at $25^{\circ} \mathrm{C}$ by Cetin and Odabasi (2007) in comparison to $\log K_{\mathrm{OA}}=11.97$ for BDE-183 at the same temperature). Accordingly, BDE209 in Arctic air should be in the MP domain, with a constant of $\log K_{\mathrm{PSM}}(-1.53)$ and the corresponding $\phi_{\mathrm{PSM}}(0.23$ if TSP $=10 \mu \mathrm{g} \mathrm{m}^{-3}$ is assumed). This prediction was remarkably in agreement with monitoring data for BDE-209 measured in Arctic air at Alert, Canada from 2007 to 2009 with a temperature range between 10 and $-50^{\circ} \mathrm{C}$ (NCP 2013), lower than the value of $t_{\mathrm{TH} 2}$ for BDE-209 (see Fig. 5). The comparisons between the predicted values and the monitoring data at Alert for other values of TSP $\left(5\right.$ and $2 \mu \mathrm{g} \mathrm{m}^{-3}$ ) given in Fig. S15 also showed great consistency. It should be stressed that the figure shows values of $\log K_{\mathrm{PE}}$ of BDE209 are from 3.06 at $10^{\circ} \mathrm{C}$ to 8.36 at $-50^{\circ} \mathrm{C}$ calculated by Eq. (3), which means that the values of $K_{\mathrm{PE}}$ are from more than 5 orders at $10^{\circ} \mathrm{C}$ to 10 orders at $-50^{\circ} \mathrm{C}$ of magnitude higher than the monitoring data, a huge error that cannot be tolerated. The corresponding values of $\phi_{\mathrm{PE}}$ are 1, indicating that BDE-209 are all in particle phase in the Arctic air predicted by the equilibrium equation, which was not the case 
for the monitoring data. In other words, the maximum value 0.23 of $\phi_{\text {PSI }}$ indicates that, from our prediction, more than half BDE-209 $(\sim 0.77)$ is in gas phase in Arctic air, which was confirmed by the monitoring data shown in Fig. 5 .

We also studied the G/P partition of the 10 PBDEs (BDE$28,-47,-66,-85,-99,-100,-153,-154,-183$, and -209$)$ in the Arctic atmosphere over the East Greenland Sea in August and September 2009 with a temperature range between $-0.5^{\circ} \mathrm{C}$ and $+6.5^{\circ} \mathrm{C}$ (Möller et al., 2011). We calculated the values of $\log K_{\mathrm{PS}}, \log K_{\mathrm{PE}}$, and $\log K_{\mathrm{PR}}$ as functions of $\log K_{\mathrm{OA}}$, and the results are shown in Fig. S16. Once again, the equation of $\log K_{\mathrm{PS}}$ had a better performance than the equation of $\log K_{\mathrm{PE}}$, especially for those congeners in the NE domain with $\log K_{\mathrm{OA}} \geq \log K_{\mathrm{OA} 1}$.

\section{Conclusions and discussion}

\subsection{G/P partitioning of PBDEs in global air}

The section At a Glance in the Supplement presents G/P partition coefficients of PBDEs ( $\log K_{\mathrm{PS}}$ and $\left.\log K_{\mathrm{PE}}\right)$ as functions of $\log K_{\mathrm{OA}}$ at ambient temperature ranging from -50 to $+50^{\circ} \mathrm{C}$, which can be applied at any sites worldwide (the top middle panel, similar to Fig. 1). The three squares in the panel designate the $\log K_{\mathrm{P}}-\log K_{\mathrm{OA}}$ graphs with three different temperature ranges: 0 to $+50,-30$ to +30 , and -50 to $0^{\circ} \mathrm{C}$, representing the tropical and subtropical climate zones, warm temperate climate zone, and boreal and tundra climate zones, respectively. Monitoring data $\left(\log K_{\mathrm{PM}}\right)$, their regression data $\left(\log K_{\mathrm{PR}}\right)$, and the predicted results $\log K_{\mathrm{PS}}$ and $\log K_{\mathrm{PE}}$ in the three different temperature zones are presented in the figure: the site Guangzhou, China, within the subtropical climate zone, shown in the top-left panel; the site Harbin, China, within the warm temperate climate zone, shown in the bottom panel; and the site Alert, Canada, within tundra climate zone, shown in the top-right panel, all introduced in the previous sections. The data at these three sampling sites all indicated that the curve of our new equation $\left(\log K_{\mathrm{PS}}\right)$ is superior to the equilibrium equation $\left(\log K_{\mathrm{PE}}\right)$ in G/P prediction of partitioning behavior for PBDEs in global air, at the sites in warm temperate, boreal, and tundra climate zones.

\subsection{Equilibrium state vs. steady state}

Harner and Bidleman (1998) developed Eq. (3), which was able to predict, for the first time, the partition coefficients of selected SVOCs in air under the conditions of equilibrium between gas and particle phases. Four years later, Harner and Shoeib (2002) used this equation to predict the partitioning behavior of $11 \mathrm{PBDE}$ congeners at $25^{\circ} \mathrm{C}$ and $0{ }^{\circ} \mathrm{C}$, the results of which, along with the results from our new equation under steady state, are given in Fig. S17 in the Supplement. As shown in the figure, the equilibrium Eq. (3) predicted that, at $0^{\circ} \mathrm{C}$, the particle fraction of PBDE congeners can reach as high as $\sim 1$, which means that PBDE congeners can be completely sorbed to the particles. According to our new Eq. (31) under steady state, however, the maximum particle fraction of PBDE congeners was about 0.42 when $\log K_{\mathrm{OA}} \geq \log K_{\mathrm{OA} 2}$, which was less than half of the highest values predicted by Eq. (3). In other words, we predict that the maximum particle fraction of PBDE congeners in air cannot be more than $50 \%$ under steady state if TSP $<30 \mu \mathrm{g} \mathrm{m}^{-3}$ (See Fig. S3 in the Supplement). In order to support their prediction results, Harner and Shoeib (2002) used the monitoring data of gaseous and particle-bound PBDEs in Great Lakes air at $20 \pm 3^{\circ} \mathrm{C}$ (Strandberg et al., 2001). However, as demonstrated in Fig. S14, the prediction by our new equation is much accurate than those by the equilibrium equation. This suggests that PBDEs in the Great Lakes atmosphere were in the steady state, not in the equilibrium state.

In brief, we cannot treat the gas and particle phases as a closed system for studying G/P partitioning behavior of PBDEs since the third compartment, the surface of the earth, has to be considered. If the non-equilibrium term, $\log \alpha$, in Eq. (31) cannot be ignored, then the fugacities of PBDEs in gas and particle phases are not equal, indicating that the system is not at equilibrium but at steady state. For some lessbrominated PBDEs (such as BDE-17 and -28) at certain temperature, the values of $\log \alpha$ is small enough in comparison to the value of $\log K_{\mathrm{PE}}$ in Eq. (31), which is considered as a small perturbation; the system can be considered as equilibrium.

\subsection{The maximum partition coefficient}

In our previous study ( $\mathrm{Li}$ and Jia, 2014), we predicted for the first time by an empirical approach the existence of a maximum partition coefficient that every PBDE congener can reach, and was wrongly termed as "saturation state". This prediction was confirmed in this study by a theoretical approach. As shown in Fig. 1, the logarithm of the maximum partition coefficient $\log K_{\text {PSM }}$ is equal to -1.53 (or $K_{\mathrm{PSM}}=0.03$ ) when $\log K_{\mathrm{OA}} \geq \log K_{\mathrm{OA} 2}$ (12.5 for all PBDE congeners), or equally when the ambient temperature is smaller than or equal to $t_{\mathrm{TH} 2}$, which is from $-34.5^{\circ} \mathrm{C}$ for BDE- 17 to $15^{\circ} \mathrm{C}$ for BDE- 183 , and cannot increase linearly along with increase of $\log K_{\mathrm{OA}}$ as predicted by the straight line of $\log K_{\mathrm{PE}}$. The difference of prediction data between these two equations can be very great. For example, as shown in Fig. 1, the difference can reach as high as $\sim 5.5$ orders of magnitude when $\log K_{\mathrm{OA}}=17$. Obviously, the state in the MP domain is a steady state, but not an equilibrium state since the fugacities of PBDEs in gas and particle phases are not equal.

The best example is the case for BDE-209 in the Canadian Arctic site Alert predicted by our new steady equation discussed previously (Fig. 5). In fact, this is true for any PBDE congener, not only for BDE-209. As shown in Fig. 1, the blue square with a temperature range of -50 to $0{ }^{\circ} \mathrm{C}$ 


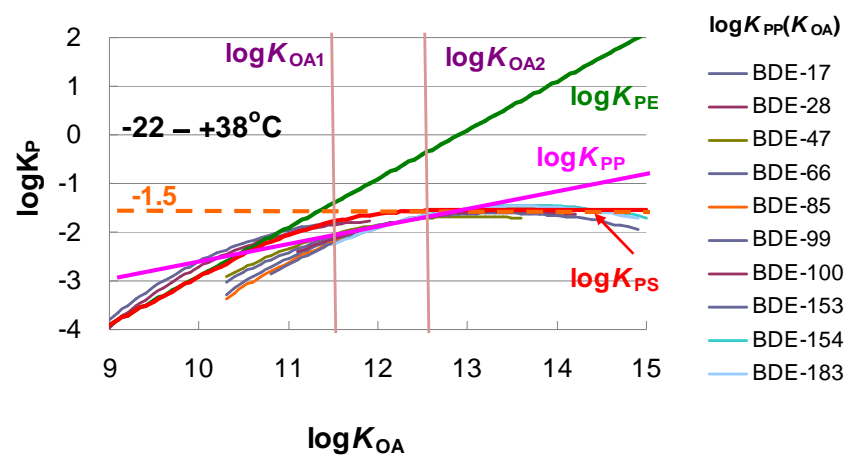

Figure 6. Variation of $\log K_{\mathrm{PS}}$ (the thick red line, given by Eq. 31), $\log K_{\mathrm{PE}}$ (the thick dark green line, given by Eq. 3 ), and $\log K_{\mathrm{PP}}$ (the thick pink line, given by Eq. 6 ) as functions of $\log K_{\mathrm{OA}}$. The functions of $\log K_{\mathrm{PP}}\left(K_{\mathrm{OA}}\right)$ (the thin lines, given by Eq. 8 ) vs. $\log K_{\mathrm{OA}}$ for $10 \mathrm{PBDE}$ congeners in Harbin air at a temperature range of -22 to $+28^{\circ} \mathrm{C}$ are also included.

could most likely be the situation for the Arctic atmosphere. Fig. 2 shows that, for the seven PBDE congeners (BDE-66, $-85,-99,-100,153,-154$, and -183$), t_{\mathrm{TH} 2}>0{ }^{\circ} \mathrm{C}$. Thus, we predict that as the $\mathrm{G} / \mathrm{P}$ partitioning behavior is considered, these seven PBDE congeners do not behave differently in the Arctic air, and are all have the same partition coefficient, $\log K_{\mathrm{PSM}}=-1.53$. Unfortunately, there are no data for the PBDE congeners other than BDE-209 available for confirmation of this prediction in the Arctic air.

\subsection{Comparison to the empirical equations}

The two empirical Eqs. (6 and 8) have been successfully applied to predict the values of $K_{\mathrm{P}}$ for PBDEs in the air of China and other countries in the north temperate zone and also at an Arctic site in East Greenland Sea (Li and Jia, 2014). The Eq. (31) for $\log K_{\mathrm{PS}}$ derived in this study is superior to these empirical equations $\log K_{\mathrm{PP}}$ and $\log K_{\mathrm{PP}}\left(K_{\mathrm{OA}}\right)$ in two ways. First, steady-state Eq. (31) was derived theoretically, and secondly, this steady-state equation can be used at any ambient temperature, from the Equator to polar regions, while the empirical equations can only be used at a temperature range of -22 to $+38^{\circ} \mathrm{C}$.

A comparison between steady-state Eq. (31) for $\log K_{\mathrm{PS}}$ and empirical equations $\log K_{\mathrm{PP}}$ given by Eq. (6) and $\log K_{\mathrm{PP}}\left(K_{\mathrm{OA}}\right)$ given by Eq. (8) in Harbin air at a temperature range of -22 to $+28^{\circ} \mathrm{C}$ is presented in Fig. 6, and the equilibrium equation $\log K_{\mathrm{PE}}$, given by Eq. (3), is also included for comparison. It is evident from Fig. 6 that the straight line of $\log K_{\mathrm{PP}}$ deviates apparently from the straight line $\log K_{\mathrm{PE}}$ at $\log K_{\mathrm{OA}}=\log K_{\mathrm{OA} 1}$ and increases linearly with $\log K_{\mathrm{OA}}$. Different lines of $\log K_{\mathrm{PP}}\left(K_{\mathrm{OA}}\right)$ for different PBDE congeners are able to predict the G/P partitioning behavior of PBDE more accurately than the straight $\operatorname{line} \log K_{\mathrm{PP}}$. It is interesting to note that the different lines of $\log K_{\mathrm{PP}}\left(K_{\mathrm{OA}}\right)$ for different PBDE congeners change their trends along with the single line of steady-state equation $\log K_{\mathrm{PS}}$, which is the best equation that can be used to predict the G/P partitioning behavior of all PBDE congeners and at all ranges of ambient temperature.

\subsection{The limitation of applications}

In order to derive Eq. (31), several assumptions were made, which include, among others, that the G/P partitioning reached steady state and that the annual rainfall was $0.5 \mathrm{~m} \mathrm{yr}^{-1}, f_{\mathrm{OM}}=0.1, C=5$. This equation, however, has been successfully applied in all situations that we discussed in this study, in which some of the assumptions were not satisfied. We should be aware, however, that the situations in which some abnormal conditions exist, such as heavy wind, heavy rains, or sampling sites close to e-waste or PBDE manufactures, are best treated separately. For example, as described in the previous section, the constant $C$ should be changed from 5 to 50 in Eq. (5) for Site Waliguan. The reason why a much higher value of $C$ was used at this site is possibly due to the high wind speed there. At Waliguan, the annual average wind speed reaches $4.6 \mathrm{~m} \mathrm{~s}^{-1}$ and northwest wind speeds of $>10 \mathrm{~m} \mathrm{~s}^{-1}$ occur quite often in the winter and spring seasons (http://gaw.empa.ch/gawsis/reports.asp? StationID=12), much higher than the other sites. There may be an analytic equation to determine the relationship between the parameter $C$ and the wind speed (and possibly other factors too), but this equation is not available at present and planned for future studies. The case for the Chinese e-waste site is also worth mentioning. Our equation cannot be used at the e-waste sites and most likely at the PBDE manufacturers as well since the emissions of PBDEs at these sites could be too large and also variable with time so that the steady state cannot be reached or maintained.

It should be borne in mind that the steady state discussed here is still an idealized scenario since only dry and wet depositions were discussed in the study; other factors, such as humidity and artifacts, will also play roles to a certain extent to affect the G/P partitioning. As anticipated, results obtained from this study do not perfectly fit monitoring data. However, this study revealed the major internal factors governing the gas/particle partitioning processes for PBDEs, and explained how these processes can be more correctly treated as being in steady state rather than in equilibrium state. At the least, the steady-state model, not the equilibrium-state model, should be applied to analyze the gas/particle relationship of SVOCs, such as PBDEs. Further studies on other SVOCs, like PCBs and PAHs, are forthcoming.

\section{The Supplement related to this article is available online at doi:10.5194/acp-15-1669-2015-supplement.}


Author contributions. Y. F. Li designed the research on the new theory of G/P partitioning of PBDE in air under steady state; Y. F. Li, W. L. Ma, and M. Yang performed the research; Y. F. Li, W. L. Ma, and M. Yang analyzed data; and Y. F. Li wrote the paper, with input from W. L. Ma and M. Yang

Acknowledgements. This work was supported by the Fundamental Research Funds for the Central Universities (grant no. HIT.KISTP.201427) and the National Natural Science Foundation of China (no. 21277038). The authors thank IJRC-PTS colleagues and students for their contributions to the China POPs SAMP-II. Valuable comments and editorial work from K. Kannan from the Wadsworth Center, New York State Department of Health, and Department of Environmental Health Sciences, School of Public Health, State University of New York at Albany, J. Li from Stanford University, M. Alaee from Environment Canada, and Y. Su from the Ontario Ministry of Environment, Canada, are highly appreciated. Thanks also to D. Mackay of Trent University, Canada, for his encouragement and valuable comments when Y. F. Li (one of the authors) presented this work to Mackay's group.

Edited by: R. Ebinghaus

\section{References}

Barrie, L. A., Gregor, D., Hargrave, B., Lake, R., Muir, D., Shearer, R., Tracey, B., and Bidleman, T.: Arctic contaminants: sources, occurrence and pathways, Sci. Total Environ., 122, 174, 1992.

Bidleman, T. F.: Atmospheric processes, Environ. Sci. Technol., 22, 361-367, 1988.

Bidleman, T. F. and Foreman, W. T.: Vapor-particle partitioning of semivolatile organic compounds, in: Sources and Fates of Aquatic Pollutants, edited by: Hites, R. A. and Eisenreich, S. J., American Chemical Sot., Washington, DC, 29-56, 1987.

Bidleman, T. F. and Harner, T.: Sorption to aerosols, in: Handbook of Property Estimation Methods for Chemicals: Environmental and Health Sciences, edited by: Boethling, R. S. and Mackay, D., Lewis Publishers, Boca Raton, FL, p. 504, 2000.

Cetin, B. and Odabasi, M.: Atmospheric concentrations and phase partitioning of polybrominated diphenyl ethers (PBDEs) in Izmir, Turkey, Chemosphere, 71, 1067-1078, 2007.

Eckhardt, S., Breivik, K., Man $\varnothing$, S., and Stohl, A.: Record high peaks in $\mathrm{PCB}$ concentrations in the Arctic atmosphere due to long-range transport of biomass burning emissions, Atmos. Chem. Phys., 7, 4527-4536, doi:10.5194/acp-7-4527-2007, 2007.

Finizio, A., Mackay, D., Bidleman, T. F., and Harner, T.: Octanol-air partition coefficient as a predictor of partitioning of semi-volatile organic chemicals to aerosols, Atmos. Environ., 15, 2289-2296, 1997.

Halsall, C. J. L., Barrie, A., Fellin, P., Muir, D. C. G., Billeck, B. N., Lockhart, L., Rovinsky, F. Ya., Kononov, E. Ya., and Pastukhov, B.: Spatial and temporal variation of polycyclic aromatic hydrocarbons in the Arctic atmosphere, Environ. Sci. Technol., 31, 3593-3599, 1997.
Harner, T. and Bidleman, T. F.: Octanol-air partition coefficient for describing particle/gas partitioning of aromatic compounds in urban air, Environ. Sci. Technol., 32, 1494-1502, 1998.

Harner, T. and Shoeib, M.: Measurements of octanol-air partition coefficients $\left(K_{\mathrm{OA}}\right)$ for polybrominated diphenyl ethers (PBDEs): predicting partitioning in the environment, J. Chem. Eng. Data, 47, 228-232, 2002.

Hayakawa, K., Takatsuki, H., Watanabe, I., and Sakai, S.: Polybrominated diphenyl ethers (PBDEs), polybrominated dibenzo-p-dioxins/dibenzofurans (PBDD/Fs) and monobromo-polychlorinated dibenzo-p-dioxins/dibenzofurans (MoBPXDD/Fs) in the atmosphere and bulk deposition in Kyoto, Japan, Chemosphere, 57, 343-356, 2004.

Helm, P. A. and Bidleman, T. F.: Gas-particle partitioning of polychlorinated naphthalenes and non- and mono-ortho-substituted polychlorinated biphenyls in arctic air, Sci. Total. Environ., 342, 161-173, 2005.

Hung, H., Blanchard, P., Poole, G., Thibert, B., Chiu, C. H.: Measurement of particle-boundpolychlorinated dibenzo-p-dioxins and dibenzofurans (PCDD/Fs) in Arctic air at Alert, Nunavut, Canada, Atmos. Environ., 36, 1041-1050, 2002.

Jantunen, L. M. and Bidleman, T.: Air-water gas exchange of hexachlorocyclohexanes (HCHs) and the enantiomers of $\alpha-\mathrm{HCH}$ in Arctic regions, J. Geophys. Res., 101, 28837-28846, 1996.

Jantunen, L. M. and Bidleman, T.: Correction to "Air-water gas exchange of hexachlorocyclohexanes (HCHs) and the enantiomers of $\alpha-\mathrm{HCH}$ in arctic regions" by Liisa M. Jantunen and Terry Bidleman, J. Geophys. Res., 102, 19279-19282, 1997.

Li, Y. F. and Bidleman, T. F.: Correlation between global emissions of $\alpha$-hexachlorocyclohexane and its concentrations in the Arctic Air, J. Environ. Inform., 1, 52-57, 2003.

Li, Y. F. and Jia, H. L.: Prediction of gas/particle partition quotients of polybrominated diphenyl ethers (PBDEs) in north temperate zone air: an empirical approach, Ecotoxic. Environ. Safety, 108, 65-71, 2014.

Li, Y. F., Bidleman, T. F., Barrie, L. A., and McConnell, L. L.: Global hexachlorocyclohexane use trends and their impact on the arctic atmospheric environment, Geophys. Res. Lett., 25, 39-41, 1998.

Li, Y. F., Macdonald, R. W., Ma, J., Hung, H., and Venkatesh, S.: $\alpha$ $\mathrm{HCH}$ Budget in the Arctic Ocean: the Arctic Mass Balance Box Model (AMBBM), Sci. Total. Environ., 324, 115-139, 2004.

Li, Y. F., Harner, T., Liu, L., Zhang, Z., Ren, N. Q., Jia, H., Ma, J., and Sverko, E.: Polychlorinated biphenyls in global air and surface soil: distributions, air-soil exchange, and fractionation effect, Environ. Sci. Technol., 44, 2784-2790, 2010.

Lohmann, R., Harner, T., Thomas, G. O., and Jones, K. C.: A comparative study of the gas-particle partitioning of PCDD/Fs, PCBs and PAHs, Sci. Total. Environ., 34, 4943-4951, 2000.

Macdonald, R. W., Barrie, L. A., Bidleman, T. F., Diamond, M. L., Gregor, D. J., Semkin, R. G., Strachan, W. M., Li, Y. F., Wania, F., Alaee, M., Alexeeva, L. B., Backus, S. M., Bailey, R., Bewers, J. M., Gobeil, C., Halsall, C. J., Harner, T, Hoff, J. T., Jantunen, L. M., Lockhart, W. L., Mackay, D., Muir, D. C., Pudykiewicz, J., Reimer, K. J., Smith, J. N., and Stern, G. A.: contaminants in the Canadian Arctic: 5 years of progress in understanding sources, occurrence and pathways, Sci. Total. Environ., 254, 93-234, 2000. 
Mackay, D.: Multimedia Environmental Models: the Fugacity Approach, 2nd Edn., Taylor \& Francis, New York, p. 261, 2001.

Möller, A, Xie, Z, Sturm R, and Ebinghaus, R.: Polybrominated diphenyl ethers (PBDEs) and alternative brominated flame retardants in air and seawater of the European Arctic, Environ. Pollut., 159, 1577-1583, 2011.

NCP 2013: Canadian Arctic Contaminants Assessment Report On Persistent Organic Pollutants - 2013, edited by: Muir, D., KurtKarakus, P., and Stow, J., Northern Contaminants Program, Aboriginal Affairs and Northern Development Canada, Ottawa, ON, xxiii + 487 pp. + Annex, 2013.

Pankow, J. F.: Review and comparative analysis of the theories on partitioning between the gas and aerosol particulate phases in the atmosphere, Atmos. Environ., 21, 2275-2283, 1987.

Pankow, J. F.: Interdependence of the slopes and intercepts from $\log$-log correlations of measured gas-particle partitioning and vapor pressure - I. Theory and analysis of available data, Atmos. Environ., 26A, 1071-1080, 1992.

Pankow, J. F.: Further discussion of the octanol/air partition coefficient Koa as a correlating parameter for gas/particle partitioning coefficients, Atmos. Environ. 32, 1493-1497, 1998.

Pankow, J. F. and Bidleman, T. F.: Effects of temperature, TSP and percent non-exchangeable material in determining the gasparticle partitioning of organic compounds, Atmos. Environ., 25A, 2241-2249, 1991.

Pankow, J. F. and Bidleman, T. F.: Interdependence of the slopes and intercepts from log-log correlations of measured gas-particle partitioning and vapor pressure - I. Theory and analysis of available data. Atmos. Environ., 26A, 1071-1080, 1992.
Rissler, J., Vestin, A., Swietlicki, E., Fisch, G., Zhou, J., Artaxo, P., and Andreae, M. O.: Size distribution and hygroscopic properties of aerosol particles from dry-season biomass burning in Amazonia, Atmos. Chem. Phys., 6, 471-491, doi:10.5194/acp-6-4712006, 2006.

Strandberg, B., Dodder, N. G., Basu, I., and Hites, R. A.: Concentrations and spatial variations of polybrominated diphenyl ethers and other organohalogen compounds in Great Lakes air, Environ. Sci. Technol., 35, 1078-1083, 2001.

Su, Y., Lei, Y. D., Wania, F., Shoeib, M., and Harner, T.: Regressing gas/particle partitioning data for polycyclic aromatic hydrocarbons, Environ. Sci. Technol., 40, 3558-3564, 2006.

Tian, M., Chen, S., Wang, J., Zheng, X., Luo, X., and Mai, B.: Brominated flame retardants in the atmosphere of e-waste and rural sites in Southern China: seasonal variation, temperature dependence, and gas-particle partitioning, Environ. Sci. Technol., 45, 8819-8825, 2011.

Weschler, C. J.: Indoor/outdoor connections exemplified by processes that depend on an organic compound's saturation vapor pressure, Atmos. Environ., 37, 5455-5465, 2003.

Weschler, C. J. and Nazaroff, W. W.: Semivolatile organic compounds in indoor environments, Atmos. Environ., 42, 90189040, 2008.

Yamasakl, H., Kuwata, K., and Mlyamoto, H.: Effects of ambient temperature on aspects of airborne polycyclic aromatic, Environ. Sci. Technol., 16, 189-194, 1982.

Yang, M., Qi, H., Jia, H., Ren, N., Ding, Y., Ma, W., Liu, L., Hung, H., Sverko, E., and Li, Y. F.: Polybrominated diphenyl ethers (PBDEs) in air across China: levels, compositions, and gas-particle partitioning, Environ. Sci. Technol., 47, 8978-8984, 2013. 